\title{
Construction of Smart Management System for Large- Scale Sports Event: A Case Study of Hangzhou Asian Games
}

\author{
Jingna $\mathrm{Du}^{1}$ Jiankang Zhang $^{2 *}$ \\ ${ }^{1,2}$ School of International Economy \& Tourism Management, Zhejiang International Studies University, Hangzhou, \\ Zhejiang 310023, China \\ *Corresponding author. Email: zhangjk@zisu.edu.cn
}

\begin{abstract}
The purpose of this study is to establish an Smart management system for large-scale sports events. Through the summary of the relevant literature, this paper finds out the problems existing in the sports event management system and the factors affecting the efficiency of the event management. According to the basic composition and principle of Smart management system, the basic framework of Smart management system is established. According to the classification of the whole process management, the Smart management is applied to the operation system construction, brand management and service management of large-scale sports events. To provide reference and suggestions for the Smart management system of Hangzhou Asian Games, so as to improve the management efficiency.
\end{abstract}

Keywords: large-scale sports event, Smart management, management system, Hangzhou Asian Games

\section{PREAMBLE}

Large-scale sports event is a comprehensive gathering with large influence, large scale and high level, which is participated by a specific group according to the purpose of the sports event, through a series of preparation and management, in a certain time and place. As the time content of large-scale events is constantly improving, and it has the concept of sports health, it is more and more supported by the state and widely concerned by the society. In recent years, as an important part of the development of sports industry and an important window of national exhibition, large-scale sports events have not only become an ordinary carrier of professional sports events, but also gradually evolved into a social activity participated by the whole people. So all aspects of development have higher requirements for the management of large-scale events. At the same time, in the digital era, the Smart management of largescale events becomes more and more urgent.Improving the construction of intelligent management system is an important guarantee to promote the sustainable development and long-term planning of large-scale sports events in China. Taking the 2022 Hangzhou Asian Games as an example, this paper puts forward some suggestions on the intelligent management system to achieve the goal of excellent large-scale events through the relevant theories of event system and intelligent management.

\section{PRINCIPLES OF SMART MANAGEMENT SYSTEM FOR LARGE- SCALE SPORTS EVENTS}

Sports event management refers to the whole process of the event, using certain organization and reasonable allocation, investing in the use of resources into the management of products and related services. The purpose of the current management is to continuously improve the efficiency of the operation of sports events. Sports event management system refers to the integration and utilization of existing resources, with the help of certain management means and methods, to maximize the use of resources, and constantly improve the efficiency of sports event management system. The definition of the Smart management system of largescale sports events given in this paper is: in the overall process of sports events, with the help of Smart ways, media and technology to integrate existing resources, the management means and methods of reasonable planning for the whole process of large-scale sports events, so that the role of existing resources can be fully 
played, and ultimately achieve the goal of sports events and improve the efficiency of management System [1].

\section{CONSTRUCTION OF SMART MANAGEMENT SYSTEM FORLARGE- SCALE SPORTS EVENTS}

\subsection{Promote the construction of competition operation system and market-oriented development}

In the current situation that most large-scale events are dominated by the government, the smart management of events should be combined with the smart brain of the city where the events are held. Make a clear guiding plan for the future development and operation management of the event, increase the market-oriented operation revenue, and improve the overall operation system of the event process. As a part of the sports industry, the attributes of sports products and services determine the need to strengthen marketoriented operation. By screening and referring to big data and intelligent planning results, the event organizers can understand the needs of people at different levels and enhance the service quality of the event products, so as to promote the market-oriented development of the event. At the same time, most of the revenue from market development is from sponsorship. Through the information platform to strengthen the exchange of event information, big data fusion and intelligent calculation to promote the diversified development of the event, accelerate the reform of the event system. So that the smart management system can effectively solve the complex problems of sports brand event organization and management and the dilemma of the market operation of the event itself, and promote the construction of the event operation system. [2]

\subsection{Improve brand IP management and extend product development}

Sports IP is the specific expression of the corresponding intellectual property rights in the field of sports. In the top large-scale events, peripheral products will be launched around sports events and sports stars. Through the integration and analysis of big data and advanced technology, the smart management of brand IP promotes the development of products in various aspects, innovates competition products, and promotes the brand group orientation and competition revenue according to the needs of different groups [3]. Through the database filtering and intelligent push, we can mine the potential accepted objects. Improve the understanding of the social scope of sports industry and media, produce the consumption phenomenon of sports culture trend, and promote the IP management of sports brand.Investment and sponsorship are part of the revenue source of the event, and are the basic source of the event brand. With the help of data screening, information exchange and intelligent decision-making, attract and promote new and old investment and sponsorship, and improve brand IP management planning.

\subsection{Big data collection, development and application with the help of information platform}

As a large-scale event, information platform is an effective channel to transmit information. Internally, it is a platform to collect and flow data, which ensures the smooth flow of information during the event and improves the efficiency of event management. Keep the information platform technology evolving and intelligent, strengthen the ability of information extraction and screening, and collect and run all kinds of real-time data through the information management system to form big data. For the data mining and sustainable use of these big data, on the one hand, the proportion of data is used to grasp the focus of participants, on the other hand, the data is automatically combined and divided according to different standard categories. From the different needs and preferences included in big data, the data background can predict the audience's needs. Promote the competition information promotion and service management mode optimization, planning new direction of product innovation and development. Make the event application management more efficient and standardized.

\subsection{Strengthen the event crisis management and risk control}

Due to the long holding period of large-scale events and the long preparation time. At the same time, the political, economic and social environment may change with time. The participants of the event are many and complex, most of the time gathered in the same area. These factors bring great challenges to the risk management of sports events. In the early stage of the event, the historical database is used to screen and calculate the crisis management and intelligent prevention application of similar events to reduce the occurrence of crisis, and the early warning scheme is put forward. During the event, the whole process data monitoring and advanced equipment are used to record the actual situation of the event. In the database storage at the same time, through the information platform to quickly reach the risk prevention group, to achieve timely risk control. After the event, use the database to calculate and sort out the event crisis, make more perfect preparation for the next event, and make effective control on the whole risk of the event. 


\section{SUGGESTIONS ON THE CONSTRUCTION OF SMART MANAGEMENT SYSTEM FOR THE 2022 HANGZHOU ASIAN GAMES}

\subsection{Keep dynamic management construction}

Keep the management dynamic and promote the smart management of the Asian Games. The system construction should not only inherit the excellent management concepts and models of the past Asian Games, but also embody the innovation of traditional management concepts and concepts. On the basis of the management system of the previous Asian Games, the system needs to innovate in the aspects of smart management technology and ideas, so as to improve the advanced nature of the management system. In the whole process of the management of the Asian Games, dynamic control should be carried out through data storage, communication platform, resource integration and technology utilization. Based on the existing management concept and planning idea, the Asian Games should strengthen the integration of wisdom elements, combine the dynamic wisdom concept, knowledge, technology and other factors with excellent traditional management means and methods, carry out continuous cultivation and development, and realize the dynamic management value.

\subsection{Building smart management platform}

Through the construction of smart platform, different levels of Hangzhou Asian Games smart platform planning are formulated. The internal and external information and data are divided into different sections to provide and help information and data for different people's needs. It can provide decision-making basis for managers to achieve real-time rapid data acquisition, storage, classification, calculation and analysis, improve the efficiency of event preparation and hosting, optimize service and intelligent management. Design the characteristic application platform of Hangzhou Asian Games, reflect the design of wisdom and sense of science and technology, and give consideration to the user's personal experience. Promote users to get quick service of one-stop experience on the platform. For the external personnel of the event, the information can be effectively received, understood, conveyed and fed back. [4]

\subsection{Strengthen smart operation management}

Continuously promote the intelligent Asian Games, information system, network security, communication network and operation guarantee, and build an intelligent management system. Through the control of digital technology and intelligent management, accelerate the reform of sports event approval system, improve the relevant management system and regulations, not adapt to the new situation. It is necessary to strengthen the overall strategic planning of sports events, comprehensively improve the evaluation and supervision of the training effect of sports events, and enhance the market influence of sports events and the degree of fit with the city. Promote digital technology to guide the transformation of sports sponsorship mode, through the powerful analysis ability of digital technology, let sponsors interact with specific target audience. Based on Intelligent precise push and IP realization potential, through data mining and analysis, we can push all-round consumption information for potential consumers, thus evolving a new business system and new business model. Encourage more platform based digital enterprises to develop and improve sports event platforms in combination with the Asian Games, and promote the establishment of intelligent and diversified operation system.

\subsection{Promote digital transformation and upgrading}

Hangzhou, as a leading city in the development of information technology in China, has achieved full coverage of optical fiber network. The current Asian Games can make use of digital resources such as the local Internet and artificial intelligence in Hangzhou to promote the digital transformation of the characteristics of the Asian Games in Hangzhou. Promote the interactive service experience, and comprehensively improve the wonderful degree of sports events and the sense of audience experience. Using digital technology to improve the quality of "service products" of sports events, to attract more consumers [5]. To serve the national fitness, health sports will be promoted to the community through intelligent information, and service guidance data platform will be launched. This will enable more people to participate in sports events and enhance the participation of the whole people. Through the development of digital technology, big data is used to analyze the whole process of the event, optimize the management, promote the security intelligence, and enrich the event venues and facilities resources. The whole process of the Asian Games will be digitized and upgraded. Improve the on-site experience, attract more audiences, stimulate the consumption of surrounding areas, and improve the visibility. Promote the sustainable development of smart sports events, so that sports events have greater development space in the future.

\subsection{Improve risk early warning and control}

Risk early warning and control are the basic guarantee for the success of all kinds of large-scale events. The Asian Games is a large-scale political and complicated event participated by many countries. 
Moreover, the population is dense and the information changes quickly, which improves the risk of events. The smart management system can use the database research to analyze the risk possibility of the whole event. According to the results of data analysis, we can make risk grade evaluation, judge the risk level of all aspects of the event, and build an intelligent risk prevention system. The digital platform always maintains information exchange, improves the risk early warning system, and ensures the smooth development of the event. Even if there is a risk, the risk of the Asian Games can be controlled in time through the rapid transmission of digital advanced technology, current affairs monitoring and information platform. [6]

\section{CONCLUSION}

At present, China is facing the opportunities and challenges brought by the era of big data and the new normal of urban planning, so the country vigorously advocates the economic development of digital industry and the construction of smart management system. Sports events are an important part of sports industry. On the basis of traditional management, sports events need smart management to promote the upgrading of events. As a large-scale sports event platform displayed in the national window, the 2022 Hangzhou Asian Games needs to be based on the interaction of different elements. Through the application and improvement of smart management system and the integration of digital information, smart platform management, smart operation management, digital upgrading and transformation, risk warning and control and other smart management construction can be realized. In order to promote the smooth operation of the event management, improve the efficiency and quality of the event work, promote the satisfaction of the event participants, and achieve a better Hangzhou Asian Games management system.

\section{ACKNOWLEDGMENTS}

This work was supported by the Zhejiang Provincial Social Science Planning Project "Communication Technology Deconstruction and Practice Orientation of the Intelligent Asian Games" (20NDJC159YB).

\section{REFERENCES}

[1] Zhang Nan. Research on Guizhou smart management mode under the background of big data [J]. Journal of urban science, 2019,40 (5): 2832

[2] Zhang Jianjun, Wang Xinwu, Yang Ting. Research on intelligent management of people flow and logistics in large sports events [J]. Logistics technology, 2014,33 (7): 62-64

[3] Ma Guansheng, Liu Yue. New management concept: smart management [J]. Scientific and technological progress and countermeasures, 2013,30 (4): 1-7

[4] Song Yu. Research on innovation of sports big data integration and communication based on blockchain [J]. Journal of Chengdu Institute of physical education, 2018,44 (6): 61-67

[5] Ren Fubing. Evolution and development of information management mode -- from data management to intelligent management $[\mathrm{J}]$. Library and information work, 2017,61 (2): 41-49

[6] Jiang Xiaojuan, Li Shu. Digitalization, globalization and the future of professional sports $[\mathrm{J}]$. Journal of Shanghai Institute of physical education, 2020, 44 (3): $1-16$ 